\title{
Periorbital infections and conjunctivitis due to Panton-Valentine Leukocidin (PVL) positive Staphylococcus aureus in children
}

\author{
Pia-Alice Hoppe 1 , Leif G. Hanitsch², Rasmus Leistner ${ }^{3}$, Michaela Niebank ${ }^{4}$, Christoph Bührer ${ }^{5}$, \\ Horst von Bernuth ${ }^{1,6,7,8}$ and Renate Krüger ${ }^{1 *}$ (D)
}

\begin{abstract}
Background: Colonisation with Panton-Valentine Leukocidin expressing strains of Staphylococcus aureus (PVL + SA) is characterised by recurrent skin and soft tissue infections. While periorbital and orbital infections are common in children and frequently caused by $S$. aureus the role of PVL + SA in recurrent eye infections has not been studied. This study aimed to detect and report frequency and recurrence of periorbital or orbital infections as additional symptoms of PVL + SA colonisation in children.

Methods: We conducted a retrospective cohort study of pediatric patients who were treated for PVL + SA skin and soft tissue infection in our in- and outpatient clinics in Berlin, Germany from January 2012 to January 2017. We identified cases with periorbital or orbital infections in the year prior to the first PVL + SA evidence. In these cases, we conducted follow-up interviews by phone to determine recurrence of symptoms after the completion of decolonisation procedures.

Results: Fifty pediatric patients (age range: one week to 17 years) were evaluated and treated for PVL + SA infections in the reported time period. 19 patients (38\%) reported periorbital infection or conjunctivitis, with recurrent hordeola as the most frequent finding $(n=9 ; 18 \%)$. Reappearance of hordeola $(n=5)$ was associated with recurrence of skin and soft tissue infections and/or de novo detection of PVL + SA. No further hordeola or other eye infections occurred after successful decolonisation.

Conclusion: Our findings suggest a frequent involvement of periorbital skin in children with PVL + SA infections. Pediatric patients with recurrent periorbital infections might benefit from PVL + SA screening and consecutive decolonisation procedures.
\end{abstract}

Keywords: Panton-Valentine Leucocidin, PVL, Staphylococcus aureus, Hordeolum, Pediatrics, Eye infection, Lid abscess

\section{Background}

Periorbital and orbital infections such as hordeola, conjunctivitis, preseptal and orbital cellulitis are common infections of the eye frequently caused by Staphylococcus aureus (S. aureus) [1]. These infections are often the result of ascending infections from the nasopharynx, lacrimal sac or sinuses, common sites of $S$. aureus colonisation [2-4]. A hordeolum is an acute infection of the

\footnotetext{
* Correspondence: r.krueger@charite.de

${ }^{1}$ Department of Pediatric Pneumology, Immunology and Intensive Care,

Charité - Universitätsmedizin Berlin, Augustenburger Platz 1, 13353 Berlin, Germany

Full list of author information is available at the end of the article
}

glands of the eyelid. Hordeola are common, however, there is no exact data on the incidence in children or adults. Due to cosmetic reasons, pain, itching and swelling recurrent hordeola can have a negative impact on a child's well-being. A recent Cochrane analysis demonstrated a lack of standardised therapeutic guidelines for single or recurrent hordeola [5].

S. aureus is the predominant cause for skin and soft tissue infections (SSTI) in the world [6]. About $30 \%$ of the general population carry the facultative pathogenic commensal on their skin, mucosa and conjunctiva [7-9]. It is primarily associated with non-invasive infections such as skin abscesses, furunculosis and wound infections, less

(c) The Author(s). 2018 Open Access This article is distributed under the terms of the Creative Commons Attribution 4.0 International License (http://creativecommons.org/licenses/by/4.0/), which permits unrestricted use, distribution, and reproduction in any medium, provided you give appropriate credit to the original author(s) and the source, provide a link to the Creative Commons license, and indicate if changes were made. The Creative Commons Public Domain Dedication waiver (http://creativecommons.org/publicdomain/zero/1.0/) applies to the data made available in this article, unless otherwise stated. 
frequently with more severe infections such as sepsis, osteomyelitis and pneumonia [10]. Nasal colonisation with $S$. aureus has been described as an important risk factor in developing SSTI and eye infections [2, 11-13].

Since the 1990s there has been an increase of infections with $S$. aureus strains expressing the exotoxin Panton-Valentine Leukocidin (PVL $+\mathrm{SA})$, which are mainly characterised by recurrent SSTI [14].

Both methicillin-sensitive (MSSA) as well as methicillinresistant (MRSA) strains of $S$. aureus express the leukocidin encoded by bacteriophage genes lukS and lukF [15]. In the US, most cases reported are caused by community acquired methicillin resistant strains (CA-MRSA). Although a rise of PVL + CA-MRSA has been reported, PVL expression is still mainly associated with MSSA in Europe [16-19].

In our routine clinical care a remarkable number of children treated for PVL + SA SSTI reported multiple, recurrent and bothersome hordeola. To our knowledge, no studies on pediatric patients with PVL + SA skin infection explored the involvement of the periorbital skin or orbita. To date, there are several case reports on severe eye infections with PVL + CA-MRSA, but none with PVL + MSSA [20-22]. Reports on PVL + SA in non-threatening periorbital infections are scarce.

This study aimed to detect and report frequency and recurrence of periorbital or orbital infections as additional symptoms of PVL + SA colonisation in children.

\section{Methods}

We conducted a retrospective cohort study of pediatric patients who were treated for PVL + SA SSTI in our pediatric in- and outpatient clinics from January 2012 to January 2017. At first presentation in our outpatient clinic, parents of affected children underwent standardized interviews comprising questions on localization and frequency of SSTI and the occurrence and frequency of hordeola up to one year prior to first evidence of PVL + SA infections in the affected child. Screening swabs from anterior nares and oropharynx were taken in each patient. Patients who had been tested positive for $\mathrm{PVL}+\mathrm{SA}$ in at least one sample (naso-pharyngeal screening swabs and/or swabs from other location, e.g. material from SSTI) were included in this study. In patients with periorbital infection at presentation conjunctival swabs were taken. S. aureus was detected by standard bacterial culture. Antimicrobial susceptibilities were determined using a Vitek ${ }^{\odot} 2$ automated system and the standard criteria of the European Committee on Antimicrobial Susceptibility Testing (EUCAST). The presence of the genes encoding PVL (lukS and lukF) was assessed by polymerase chain reaction (PCR) as described previously [23]. We excluded patients who had been treated for PVL + SA based on clinical data (typical symptoms plus PVL + SA evidence in household members) but had been tested negative for PVL $+\mathrm{SA}$ in the screening swabs.

Data were collected from electronic medical records and archived files. Our main research parameter was the occurrence of an eye infection within 12 months prior to the first PVL + SA detection. We defined eye infection as self-report or diagnosis of at least one periorbital or orbital infection. We defined recurrent infection as more than two episodes during the reported time period. All patients received decolonisation measures (consisting of: topical application of mupirocin nasal ointment and antiseptic treatment of mouth, hair, skin and housing space for at least five days). Successful decolonisation was defined as two negative screening swabs plus no recurrence of SSTI. In patients with a history of eye infection we conducted follow up interviews by phone at least two months after completion of decolonisation measures to detect any recurrence of symptoms after two months. Data were processed using Microsoft ${ }^{\circ}$ Excel $^{\circledR} 2013$.

\section{Results}

From January 2012 to January 201772 children had received treatment for PVL + SA associated SSTI in our clinic. 22 of these children were treated based on clinical data alone and thus excluded from our study. The remaining 50 patients were included. Median age was 6 years (Range: one week - 17 years). $54 \%$ of patients were male $(n=27)$ and $46 \%$ female $(n=23)$. Seven children (14\%) were infected with PVL + MRSA, all others (86\%) with PVL + MSSA. In one patient (age: 17) with multiple hordeola at presentation, PVL + SA was cultured from conjunctival swabs. 19 patients (38\%) reported periorbital infections. The characteristics of these patients are summarised in Table 1. Patients suffered from eyelid abscesses $(n=5)$, preseptal cellulitis $(n=1)$, conjunctivitis $(n=3)$ and hordeola $(n=12)$. Nine of these patients $(18 \%)$ reported recurrent hordeola, with the onset of hordeola with a temporal connection to the onset of SSTI (Fig. 1). Four patients were lost to follow-up. In five patients eye infection reappeared, however, this was associated with recurrence of SSTI in all five cases, with de novo detection of PVL $+\mathrm{SA}$ in two cases. In the remaining ten patients no further hordeola or periorbital infections occurred after successful decolonisation (follow-up: 10 weeks to 36 months).

\section{Discussion}

Our study demonstrates a high frequency of periorbital infections in pediatric patients with $\mathrm{PVL}+\mathrm{SA}$ associated SSTI. Recurrent hordeola were observed in $18 \%$ of children with PVL + SA colonisation. Other manifestations comprised conjunctivitis, preseptal cellulitis and eyelid 
Table 1 Characteristics of PVL positive children with eye infections

\begin{tabular}{|c|c|c|c|c|c|c|c|c|c|}
\hline Patient & $\begin{array}{l}\text { Age at } \\
\text { diagnosis }\end{array}$ & MRSA & Hordeola & Conjunctivitis & $\begin{array}{l}\text { Preseptal } \\
\text { cellulitis }\end{array}$ & Eyelid abscess & $\begin{array}{l}\text { Recurrence } \\
\text { of SSTI }\end{array}$ & $\begin{array}{l}\text { Recurrence of } \\
\text { eye infection }\end{array}$ & $\begin{array}{l}\text { De novo } \\
\text { detection }\end{array}$ \\
\hline No. & months (years) & yes/no & $n$ & $\mathrm{n}$ & $\mathrm{n}$ & $\mathrm{n}$ & yes/no & yes/no & $\begin{array}{l}\text { yes/no/not } \\
\text { tested }\end{array}$ \\
\hline 1 & $114(9)$ & no & $>2$ & 0 & 0 & 0 & no & no & not tested \\
\hline 2 & $1(0)$ & no & 0 & 2 & 1 & 0 & no & no & not tested \\
\hline 3 & $155(12)$ & no & $>2$ & 0 & 0 & 0 & no & no & not tested \\
\hline 4 & $117(9)$ & no & $>2$ & 0 & 0 & 0 & yes & yes & not tested \\
\hline 5 & $16(1)$ & no & 1 & 0 & 0 & 0 & yes & yes & yes \\
\hline 6 & $14(1)$ & no & 0 & 1 & 1 & 0 & no & no & not tested \\
\hline 7 & $205(17)$ & no & $>2$ & 0 & 0 & 0 & yes & yes & yes \\
\hline 8 & $195(16)$ & no & 1 & 0 & 0 & 1 & Lost to follow-up & Lost to follow-up & not tested \\
\hline 9 & $80(6)$ & no & 1 & 0 & 0 & 0 & yes & yes & not tested \\
\hline 10 & $0(0)$ & yes & 0 & 2 & 0 & 0 & Lost to follow-up & Lost to follow-up & not tested \\
\hline 11 & $30(2)$ & no & 0 & 0 & 0 & 1 & no & no & not tested \\
\hline 12 & $199(16)$ & no & $>2$ & 0 & 0 & 0 & no & no & not tested \\
\hline 13 & $54(4)$ & no & $>2$ & 0 & 0 & 0 & no & no & not tested \\
\hline 14 & $9(0)$ & no & 0 & 1 & 0 & 0 & no & no & not tested \\
\hline 15 & $96(8)$ & no & $>2$ & 0 & 0 & 0 & no & no & not tested \\
\hline 16 & $54(4)$ & no & $>2$ & 0 & 0 & 0 & no & no & not tested \\
\hline 17 & $122(10)$ & no & $>2$ & 0 & 0 & 1 & yes & yes & not tested \\
\hline 18 & $73(6)$ & yes & 0 & 0 & 0 & 1 & Lost to follow-up & Lost to follow-up & not tested \\
\hline 19 & $122(10)$ & yes & 0 & 0 & 0 & 1 & Lost to follow-up & Lost to follow-up & not tested \\
\hline
\end{tabular}

abscesses. In cases with successful and sustained decolonisation of PVL + SA no further episode of an eye infection occurred.

A recent study of periorbital and orbital cellulitis from the USA ( $n=85$, children) by Foster et al. [24] found PVL + SA evidence in $85 \%(n=72)$ cases. In another study
( $n=49$, patients of all ages) by Blomquist et al. [25] the most common eye manifestations of CA-MRSA infection were preseptal cellulitis/lid abscesses and conjunctivitis. Hordeola were not evaluated in this study. A case series ( $n=9$, adult patients) from the USA by Rutar et al. [26] showed the capacity of PVL + MRSA to cause severe eye

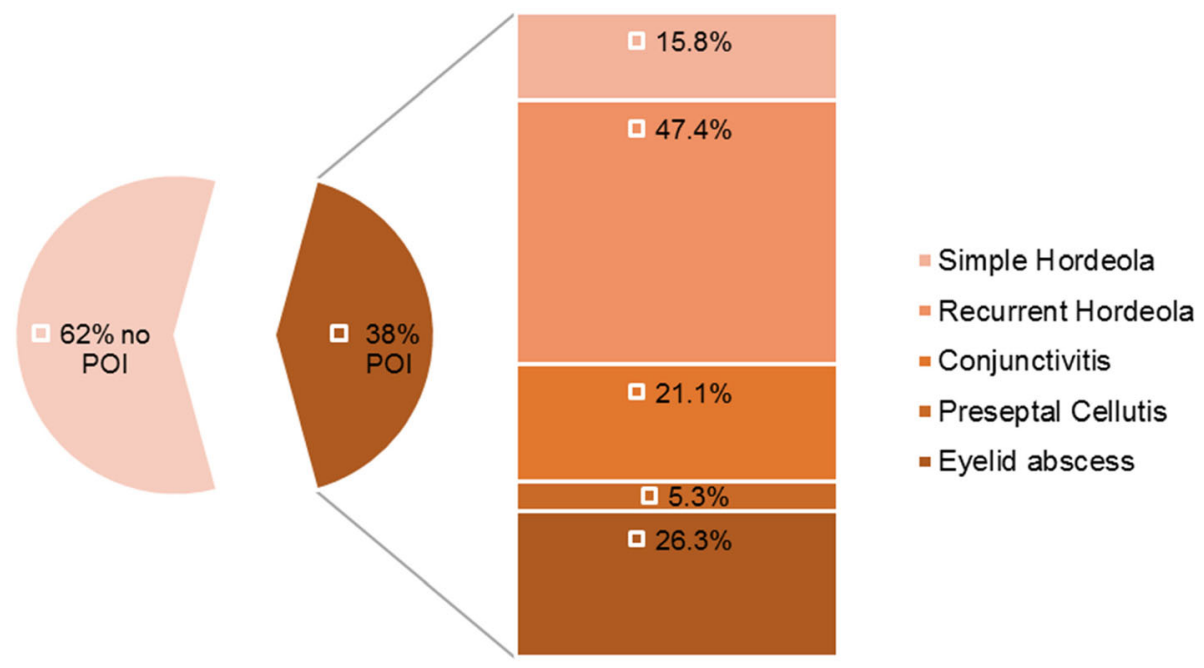

Fig. 1 Presentation of eye infection in PVL positive children. Circle: Proportion of PVL+ children $(n=50)$ with or without periorbital infection (POI). Bar: Proportion of types of POI reported by the POI cohort 
infections. Nadig et al. [27] detected a high number ( $n=22$ of 33) of PVL + MRSA in a study on eye infections in patients of all ages in India. Two case reports from the UK by Alaghband et al. [22] and from the USA by Rutar et al. [26] presented patients with severe orbital infections resulting in blindness or bacteraemia in otherwise healthy adults. Tsironi et al. [21] reported the case of a previously healthy neonate who developed orbital cellulitis with PVL + MRSA. Sueke et al. [28] reported 9.5\% PVL+SA in S. aureus isolates from bacterial keratitis in the United Kingdom.

Our data suggests that not only pediatric patients with severe but also those with recurrent but non-threatening periorbital infections (especially hordeola) should be tested for nasopharyngeal PVL + SA colonisation. In case of PVL + SA detection decolonisation measures should be recommended as described by Gillet et al. [29].

PVL detection depends on accurate sampling, culture and PCR conditions [30]. This should be taken into consideration in patients with typical symptoms but no evidence of PVL + SA.

Also, routine testing for nasopharyngeal or conjunctival colonisation with PVL + SA in patients with a history of SSTI or eye infections may be limited by significant costs of lukS/lukF PCR, especially for primary care physicians with limited budgets.

Therefore, decolonization measures can occasionally be considered in patients with a classic history of recurrent SSTI when testing for PVL + SA is not feasible or negative.

For our study, we evaluated children who presented with SSTI and were than assessed for a history of prior eye infections. Because of this selection bias we do not know the extent of PVL + SA colonisation in children with eye infections but no history of SSTI. Further study of children with recurrent eye infections could determine the frequency of PVL + SA. As a further limitation of our study, we did not include routine screening of conjunctival swabs, lid abscess material or hordeolum tissue for PVL + SA. Further studies with microbiologic testing of conjunctival swabs from symptomatic patients or tissue obtained from hordeola are required to prove the causal relationship between PVL + SA and recurrent eye infections, especially hordeola.

\section{Conclusion}

Our findings suggest a frequent involvement of periorbital skin in children with PVL + SA infections. Pediatric patients with recurrent periorbital infections might benefit from PVL + SA screening and staphylococcal decolonisation procedures.

\section{Abbreviations}

CA: community aquired; EUCAST: European Committee on Antimicrobial Susceptibility Testing; MRSA: methicillin-resistant Staphylococcus aureus;
MSSA: methicillin-sensitive Staphylococcus aureus; PCR: polymerase chain reaction; PVL: Panton-Valentine Leukocidin; SA: Staphylococcus aureus; SSTI: skin and soft tissue infections

\section{Funding}

We acknowledge support from from the German Research Foundation (DFG) and the Open Access Publication Fund of Charité - Universitätsmedizin Berlin

\section{Availability of data and materials}

Raw data can be obtained from R. Krüger (r.krueger@charite.de).

\section{Consent to publish}

Parents gave verbal informed consent to publication of study results. All couthors consented to publication of study results.

\section{Authors' contributions}

PAH contributed to data collection, analysis and wrote the manuscript. LGH, $\mathrm{MN}, \mathrm{CB}$ and $\mathrm{HvB}$ provided patient data and contributed to data analyses and interpretation, they critically reviewed the manuscript. RL performed microbiology testing, contributed to data interpretation and critically reviewed the manuscript. RK initiated the study, provided patient data, contributed to data collection and analyses and revised the manuscript. All authors read and approved the final manuscript.

\section{Ethics approval and consent to participate}

Parents gave verbal informed consent to telephone interviews, data collection and publication of study results. The study was approved by the local Ethics Committee (Charité, Berlin, Germany, EA2/190/17). Verbal consent was approved since no interventions appart from routine clinical care were performed and data were collected retrospectively from clinical charts.

\section{Consent for publication}

n/a.

\section{Competing interests}

The authors declare no competing interests.

\section{Publisher's Note}

Springer Nature remains neutral with regard to jurisdictional claims in published maps and institutional affiliations.

\section{Author details}

'Department of Pediatric Pneumology, Immunology and Intensive Care, Charité - Universitätsmedizin Berlin, Augustenburger Platz 1, 13353 Berlin, Germany. ${ }^{2}$ Department of Medical Immunology, Charité - Universitätsmedizin Berlin, Augustenburger Platz 1, 13353 Berlin, Germany. ${ }^{3}$ Department of Hygiene, Charité - Universitätsmedizin Berlin, Germany, Augustenburger Platz 1, 13353 Berlin, Germany. ${ }^{4}$ Department of Internal Medicine/Infectious Diseases and Pulmonary Medicine, Charité -Universitätsmedizin Berlin, Augustenburger Platz 1, 13353 Berlin, Germany. ${ }^{5}$ Department of Neonatology, Charité - Universitätsmedizin Berlin, Augustenburger Platz 1, 13353 Berlin, Germany. ${ }^{6}$ Sozialpädiatrisches Zentrum, Charité -

Universitätsmedizin Berlin, Berlin, Germany. ${ }^{7}$ Labor Berlin GmbH, Fachbereich Immunology, Charité -Vivantes, Berlin, Germany. ${ }^{8}$ Berlin Center for Regenerative Therapies (BCRT), Charité - Universitätsmedizin Berlin, Augustenburger Platz 1, 13353 Berlin, Germany.

Received: 16 October 2017 Accepted: 30 July 2018

Published online: 06 August 2018

\section{References}

1. Liu IT, Kao SC, Wang AG, Tsai CC, Liang CK, Hsu WM. Preseptal and orbital cellulitis: a 10-year review of hospitalized patients. J Chin Med Assoc. 2006; 69(9):415-22.

2. Roodyn L. Staphylococcal infections in general practice. Br Med J. 1954; 2(4900):1322-5.

3. Dougherty JM, McCulley JP. Comparative bacteriology of chronic blepharitis. Br J Ophthalmol. 1984;68(8):524-8. 
4. Mathias MT, Horsley MB, Mawn LA, Laquis SJ, Cahill KV, Foster J, et al. Atypical presentations of orbital cellulitis caused by methicillin-resistant Staphylococcus aureus. Ophthalmology. 2012;119(6):1238-43.

5. Lindsley K, Nichols JJ, Dickersin K. Interventions for acute internal hordeolum. Cochrane Database Syst Rev. 2013;4:Cd007742.

6. Diekema DJ, Pfaller MA, Schmitz FJ, Smayevsky J, Bell J, Jones RN, et al. Survey of infections due to Staphylococcus species: frequency of occurrence and antimicrobial susceptibility of isolates collected in the United States, Canada, Latin America, Europe, and the western Pacific region for the SENTRY antimicrobial surveillance program, 1997-1999. Clin Infect Dis. 2001;32(Suppl 2):S114-32.

7. Mino de Kaspar H, Koss MJ, He L, Blumenkranz MS, Ta CN. Antibiotic susceptibility of preoperative normal conjunctival bacteria. Am J Ophthalmol. 2005;139(4):730-3.

8. Gorwitz RJ, Kruszon-Moran D, McAllister SK, McQuillan G, McDougal LK, Fosheim GE, et al. Changes in the prevalence of nasal colonization with Staphylococcus aureus in the United States, 2001-2004. J Infect Dis. 2008; 197(9):1226-34.

9. Chang VS, Dhaliwal DK, Raju L, Kowalski RP. Antibiotic resistance in the treatment of Staphylococcus aureus keratitis: a 20-year review. Cornea. 2015;34(6):698-703.

10. Tong SY, Davis JS, Eichenberger E, Holland TL, Fowler VG Jr. Staphylococcus aureus infections: epidemiology, pathophysiology, clinical manifestations, and management. Clin Microbiol Rev. 2015;28(3):603-61.

11. Kluytmans J, van Belkum A, Verbrugh H. Nasal carriage of Staphylococcus aureus: epidemiology, underlying mechanisms, and associated risks. Clin Microbiol Rev. 1997;10(3):505-20.

12. Toshkova K, Annemuller C, Akineden O, Lammler C. The significance of nasal carriage of Staphylococcus aureus as risk factor for human skin infections. FEMS Microbiol Lett. 2001;202(1):17-24.

13. Wertheim HF, Melles DC, Vos MC, van Leeuwen W, van Belkum A, Verbrugh $\mathrm{HA}$, et al. The role of nasal carriage in Staphylococcus aureus infections. Lancet Infect Dis. 2005;5(12):751-62.

14. Shallcross LJ, Fragaszy E, Johnson AM, Hayward AC. The role of the Pantonvalentine leucocidin toxin in staphylococcal disease: a systematic review and meta-analysis. Lancet Infect Dis. 2013;13(1):43-54.

15. Prevost G, Cribier B, Couppie P, Petiau P, Supersac G, Finck-Barbancon V, et al. Panton-valentine leucocidin and gamma-hemolysin from Staphylococcus aureus ATCC 49775 are encoded by distinct genetic loci and have different biological activities. Infect Immun. 1995;63(10):4121-9.

16. Moran GJ, Krishnadasan A, Gorwitz RJ, Fosheim GE, McDougal LK, Carey RB, et al. Methicillin-resistant S. Aureus infections among patients in the emergency department. N Engl J Med. 2006;355(7):666-74.

17. Witte W, Strommenger B, Cuny C, Heuck D, Nuebel U. Methicillin-resistant Staphylococcus aureus containing the Panton-valentine leucocidin gene in Germany in 2005 and 2006. J Antimicrob Chemother. 2007;60(6):1258-63.

18. Rasigade JP, Laurent F, Lina G, Meugnier H, Bes M, Vandenesch F, et al. Global distribution and evolution of Panton-valentine leukocidin-positive methicillin-susceptible Staphylococcus aureus, 1981-2007. J Infect Dis. 2010; 201(10):1589-97.

19. Shore AC, Tecklenborg SC, Brennan Gl, Ehricht R, Monecke S, Coleman DC Panton-valentine leukocidin-positive Staphylococcus aureus in Ireland from 2002 to 2011: 21 clones, frequent importation of clones, temporal shifts of predominant methicillin-resistant S. Aureus clones, and increasing multiresistance. J Clin Microbiol. 2014:52(3):859-70.

20. Rutar T, Zwick OM, Cockerham KP, Horton JC. Bilateral blindness from orbital cellulitis caused by community-acquired methicillin-resistant Staphylococcus aureus. Am J Ophthalmol. 2005;140(4):740-2.

21. Tsironi EE, Zacharaki F, Grivea IN, Tachmitzi SV, Michoula AN, Vlychou M, et al. European ST80 community-associated methicillin-resistant Staphylococcus aureus orbital cellulitis in a neonate. BMC Ophthalmol. 2012;12:7.

22. Alaghband P, Oworu O. An unusual case of orbital cellulitis due to Panton valentine Leucocidine producing Staphylococcus aureus. Eye (Lond). 2013; 27(1):108-9.

23. Becker K, Larsen AR, Skov RL, Paterson GK, Holmes MA, Sabat AJ, et al. Evaluation of a modular multiplex-PCRmethicillin-resistant Staphylococcus aureus detection assay adapted for mecCdetection. J Clin Microbiol. 2013 Jun;51(6):1917-9.

24. Foster CE, Yarotsky E, Mason EO, Kaplan SL, Hulten KG. Molecular Characterization of Staphylococcus aureus Isolates From Children With Periorbital or Orbital Cellulitis. J Pediatric Infect Dis Soc. 2017. Epub ahead of print.
25. Blomquist PH. Methicillin-resistant Staphylococcus aureus infections of the eye and orbit (an American ophthalmological society thesis). Trans Am Ophthalmol Soc. 2006;104:322-45.

26. Rutar T, Chambers HF, Crawford JB, Perdreau-Remington F, Zwick OM, Karr $M$, et al. Ophthalmic manifestations of infections caused by the USA300 clone of community-associated methicillin-resistant Staphylococcus aureus. Ophthalmology. 2006;113(8):1455-62.

27. Nadig S, Velusamy N, Lalitha P, Kar S, Sharma S, Arakere G. Staphylococcus aureus eye infections in two Indian hospitals: emergence of ST772 as a major clone. Clin Ophthalmol. 2012;6:165-73.

28. Sueke H, Shankar J, Neal T, Winstanley C, Tuft S, Coates R, et al. lukSF-PV in Staphylococcus aureus keratitis isolates and association with clinical outcome. Invest Ophthalmol Vis Sci. 2013;54(5):3410-6.

29. Gillet Y, Dumitrescu O, Tristan A, Dauwalder O, Javouhey E, Floret D, et al. Pragmatic management of Panton-valentine leukocidin-associated staphylococcal diseases. Int J Antimicrob Agents. 2011;38(6):457-64.

30. Sewell DL, Potter SA, Jacobson CM, Strausbaugh $\sqcup$, Ward $\Pi$. Sensitivity of surveillance cultures for the detection of methicillin-resistant Staphylococcus aureus in a nursing-home-care unit. Diagn Microbiol Infect Dis. 1993;17(1):53-6.

\section{Ready to submit your research? Choose BMC and benefit from:}

- fast, convenient online submission

- thorough peer review by experienced researchers in your field

- rapid publication on acceptance

- support for research data, including large and complex data types

- gold Open Access which fosters wider collaboration and increased citations

- maximum visibility for your research: over $100 \mathrm{M}$ website views per year

At $\mathrm{BMC}$, research is always in progress.

Learn more biomedcentral.com/submissions 